\title{
Ricardo Palma y San Marcos
}

Carlos Alberto Pérez Garay 
Licenciado en Historia por la Universidad Nacional Mayor de San Marcos. Realiza labores de investigación en el Instituto de Estudios Peruanos. 
A lo largo de sus cuatro siglos y medio de vida institucional, la Universidad de San Marcos ha sido siempre motivo de orgullo y preocupación de distintas generaciones de intelectuales peruanos y extranjeros.

Así, pues, desde los tiempos coloniales de Diego de Salinas y Pedro Peralta Barnuevo hasta la época republicana de Raúl Porras y Mario Vargas Llosa, muchos personajes del saber humanístico han reconocido -a ciencia cierta- los méritos académicos, el aporte cultural y el valioso pasado de la Decana de América, lo que ha llevado a convertirla en el centro de atención para sus diversas obras.

Precisamente, uno de los intelectuales peruanos que mayor simpatía y afecto tuvo con San Marcos fue don Ricardo Palma, autor de las famosas Tradiciones Peruanas. Nacido en Lima en 1833 -ocho años después de la batalla de Ayacucho- el escritor limeño tuvo, desde sus primeros años de vida, un contacto cercano con la primera universidad del Perú. Inicialmente ubicada en la calle de Puno -hoy jirón Ayacucho- estuvo a escaso metros del antiguo local sanmarquino, lugar en donde hoy se levanta el edificio del Congreso de la República. Posteriormente, tras alejarse de esa vivienda, el futuro tradicionista pasaría a vivir cerca de las inmediaciones del recinto universitario, en la calle del Rastro de San Francisco (el actual jirón Ancash) y en la calle del Arzobispo (el actual jirón Junín).

Sus constantes correrías infantiles lo llevaron a conocer casi de lejos a distintos personajes del local universitario (catedráticos 
y alumnos) quienes solían andar perfectamente vestidos de levita y frac, los llamados "hombres de traje negro", los cuales, al parecer, le dieron una grata impresión.

Al pasar a la etapa de la adolescencia, Palma debió de advertir, como muchos jóvenes peruanos, la serie de obras emprendidas por el gobierno del general Ramón Castilla, quien amparado por los ingentes ingresos del guano encaminaba al país hacia un período de paz y progreso. Precisamente, en medio de este clima propicio, varios jóvenes -atraídos por las facilidades que daba el Estado (becas, semibecas) - decidieron cursar estudios superiores con el fin de alcanzar un grado o titulo universitario que les serviría de mucho en su vida. Animado por algunos amigos $y$, quien sabe, por los consejos de su padre, el joven Palma decidió apostar por los estudios de alto nivel en uno de los mejores centros de enseñanza de la capital: el Convictorio de San Carlos, que hacía entonces el papel de la Facultad de Derecho de San Marcos. Su ingresó a San Carlos se produjo en 1849, matriculándose en la condición de becario, ya que no contaba con los medios económicos para costear sus estudios. Como muchos estudiantes, el futuro escritor pretendió alcanzar la profesión de abogado, o en su defecto tener los estudios suficientes para ejercer la labor periodística, carrera que ejercía paralelamente, por entonces, en algunos tabloides de la capital. Con mucho esfuerzo, Palma cumpliría al máximo sus obligaciones de estudiante, las cuales eran observadas muy de cerca por Bartolomé Herrera, rector de ese centro de estudios y uno de los eminentes intelectuales peruanos de aquella época.

A pesar de ello, el joven estudiante al darse cuenta de que los estudios eran muy prolongados, no pudo resistirse a aceptar un puesto burocrático en el Cuerpo Político de la Armada, motivo por el cual dejaría inconclusos sus estudios superiores en 1853. Por cierto, el propio Palma ha dejado prueba testimonial de 
ello. En efecto, en su "Autobiografía", el autor de las Tradiciones expresó que: "Amorcillos de estudiante me obligaron a dejar la Universidad...". Igualmente en su tradición "El pleito de los pulperos", escribió: "Algo a que no di por entonces importancia contóme, cuando era estudiante (porque han de saber ustedes que, aunque lo disimulo mucho, yo he estudiado)..."2. Según Oswaldo Holguín, Palma "sin duda, empleo el termino "estudiante" en el sentido de cursante de estudios superiores, vale decir universitario"3.

Ahora bien, habiendo dejado de lado sus estudios superiores, Palma no pudo dejar de nombrar y hacer referencia -en más de una ocasión- a la principal institución universitaria del Perú y a sus personajes más destacados. En la tradición "El patronato de San Marcos", el escritor nos remonta al pasado colonial (1574) para contarnos acerca de la elección del Santo Patrón de la Universidad, al apóstol Marcos, el cual fue elegido dentro de una lista de santos del mundo católico. Por otro lado, en su tradición "Vítores", Palma trae a la memoria la costumbre de los vítores que se llevaban a cabo cuando se elegía rector de San Marcos, "elección disputada a veces con calor, o se confería por oposición alguna cátedra, echábanse a pasear por las calles con bandas de música, quemando cohetes y gritando iVitor al doctor Fulano!

Por otra parte, en su tradición "Los padrinos", Palma nos ofrece también un cuadro sobre la actuación de estos personajes, quienes estaban muy de moda en la época colonial. En esa tradición, el escritor dio cuenta, de que "en la Real y Pontificia

I Ricardo Palma. "Autobiografía”, en Las mejores tradiciones peruanas. Barcelona: Casa Editorial Maucci, (1917?), p. 8.

2 Tradiciones Peruanas Completas. Madrid: Aguilar, 1964, p. 740.

3 Oswaldo Holguín Callo. Tiempos de infancia y bohemia. Ricardo Palma (18331860). Lima: PUCP Fondo Editorial, 1994, p, 125. 
Universidad de San Marcos llevaba padrino todo aspirante a grado en cualquiera de las facultades". Asimismo, en la tradición "La apología del pichón Palomino", Palma señala algunos episodios de la vida de don José Pastor de Larrinaga, protocirujano y médico sanmarquino, autor de la Oración gratulatoria que en 1781 dirigió la Real y Pontifia Universidad de San Marcos al Virrey Jáuregui. Mientras que en la tradición "Una ceremonia del jueves santo", el tradicionista señaló que la capilla de Nuestra Señora de la Antigua, ubicada en la Catedral de Lima, donde se realizaban los grados universitarios, fue construido y refaccionado por Matías Maestro, gracias al dinero proporcionado por la Pontificia Universidad de San Marcos.

Si bien en estas tradiciones se hace referencia a la Universidad, habría que señalar la importancia de unas anotaciones consignadas por Palma en "Vítores". En esta tradición (1879), el escritor hizo referencia a que la universidad de Lima (San Marcos) tuvo ocasión de conferirle dos doctorados: uno en Jurisprudencia y otro en Letras. Dato importante en la vida de Palma, que es corroborado por su testimonio, es la tradición "Entre si juro o no juro", en la cual señala: "A mí me lo han dicho quienes tienen obligación de saberlo, que yo no soy de la carrera, por mucho que la Universidad de mi tierra me haya honrado con el obsequio del diploma de doctor en Jurisprudencia”. Hecho que demuestra el profundo respeto y aprecio que tuvo la Universidad con una de las celebridades peruanas más reconocidas a nivel continental.

Al iniciarse la Guerra con Chile la relación entre Palma y la Universidad se volvió cada vez más cordial. Así, en 1881, al ser ocupada la capital por el ejército invasor, el escritor no pudo evitar mostrar su profunda molestia por el saqueo de San Marcos, de donde fue extraída su valiosa Biblioteca, el gabinete anatómico de la Escuela de Medicina y un sinnúmero 
de bienes y utensilios ${ }^{4}$. Firmada la paz con los chilenos, Palma fue nombrado director de la Biblioteca Nacional por el general Iglesias. Siendo la cabeza de esta institución, el escritor apoyó la reorganización de San Marcos, estando pendiente de las actividades académicas y del desempeño de algunos de sus amigos catedráticos.

Precisamente, una de las noticias que Palma logró enterarse sobre San Marcos fue acerca de la sustentación, en 1890, de una tesis doctoral en la Facultad de Letras a cargo del joven Maximiliano Oyola, que llevaba por título La Mujer. En este trabajo, su autor, influenciado por las ideas feministas europeas, logró causar enorme revuelo en el público asistente, integrado en su mayoría por personas de línea conservadora, quienes mostraron su total rechazo a esta tesis por presentar ideas disociadoras y subversivas. Movido por la curiosidad, el tradicionista leyó el trabajo de Oyola, comprobando que mucho de lo que se decía no era verdad, razón por la cual mostró su crítica contra las autoridades de la Facultad de Letras por promover el dogmatismo, la intolerancia y negar la libertad de pensamiento ${ }^{5}$. Sin embargo, aquella crítica no duraría mucho tiempo. A principios de la década de 1890, su hijo, Clemente ingresó a cursar estudios de Jurisprudencia y Filosofía en esa Facultad, lo cual fue motivo de alegría para el escritor limeño.

Al llegar el siglo XX, la relación entre el tradicionista y San Marcos continuó siendo estrecha. Es más, su hijo Ricardo ingresó a la Escuela de Medicina de San Fernando, de la que egresaría allá, por la década de 1910.

4 Palma a Nicolás de Piérola. Lima, 4 de marzo de 1881, en Ricardo Palma. Cartas Inéditas. Introducción y notas de Rubén Vargas Ugarte. Lima: Milla Batres, 1964 , p. 20.

5 Tr. Borrasca en un vaso de agua. TPC, p. 1496. 
Precisamente, en aquel año se dará tiempo para asistir a la Facultad de Letras, a fin de observar la brillante sustentación de la tesis doctoral La historia en el Perú a cargo de su amigo, José de la Riva Agüero, a quien consideró como un "inteligentísimo joven" y "gran cerebro"6.

En 1912, al renunciar a la Biblioteca Nacional, Palma se fue a vivir al barrio de Miraflores. Hasta ese lugar lo irán a visitar muchos amigos vinculados a San Marcos, como el propio Riva Agüero, Mariano Cornejo, Oscar Miro Quesada, Julio C. Tello (amigo de su hijo Ricardo) y Javier Prado Ugarteche. Alejado de la ciudad, pocas serán las veces que el escritor irá al centro. Una de sus ocasionales visitas a la capital ocurrirá el 31 de julio de 1912 con motivo de la invitación de un grupo de jóvenes estudiantes americanos. En dicha visita, Palma se dirigió al Centro Universitario de San Marcos, lugar en donde pronunció un emotivo discurso para un nutrido público universitario de Argentina, Brasil, Uruguay, Ecuador, Bolivia, Centroamérica, Venezuela, Paraguay, Cuba y Panamá.

Con el trascurrir de los años el achacoso octogenario seguirá siendo visitado frecuentemente por varias personas, entre las cuales se encontran algunos estudiantes sanmarquinos, como Raúl Porras Barrenechea y Guillermo Luna Cartland, redactores de la revista Alma Latina. Sin embargo, a pesar de ello, serán contadas las ocasiones en que Palma aparecerá en una actividad pública, tanto es así que dejará de ir a algunas sesiones de la Academia Peruana de la Lengua debido a su delicada salud. Así, el 18 de diciembre de 1918, al reunirse los académicos en la Universidad de San Marcos, para la sesión

6 Palma a Menéndez y Pelayo. Lima 6 de marzo de 1906, en Ricardo Palma. Epistolario. Lima: Cultura Antártica, S.A. 1949. T. I, p.I01. 
inaugural, el escritor no asistirá por su mala salud, siendo el encargado de leer su discurso Víctor Andrés Belaúnde ${ }^{7}$.

Palma falleció el 6 de octubre de 1919 en su residencia de Miraflores. A su funeral concurrieron importantes personajes del medio, como el rector de San Marcos, Javier Prado, quien a nombre de su institución se hizo presente llevando un imponente arreglo floral. Ahora bien, a punto de cumplirse cien años de su muerte, la vida y obra de Palma se mantienen siempre presentes en el recuerdo y la memoria de San Marcos, una de las instituciones más queridas por el tradicionista.

7 Oswaldo Holguín Callo. "Palma y Riva Agüero: calas a su amistad”, en Páginas sobre Ricardo Palma. Lima: Universidad Ricardo Palma Editorial Universitaria, 2001, p. 198. 